\title{
Free-Time Management among Master's Degree Students of Georgia
}

\author{
Natalia Kharadze \\ $\mathrm{PhD}$ in Economics, Manager of HPML, Professor of TSU
}

Ekaterine Gulua

$\mathrm{PhD}$ in Economics, CEO of HPML, Professor of TSU

Dugladze Davit

PhD Student of GTU

\begin{abstract}
Attitude to time management in modern literature becomes more and more topical. According to (Orlikowsky and Yates 2002), increased competition causes the necessity of effective utilization of time. The part of free time in time budget of employed Master's degree students becomes smaller, and the importance of free time is almost disregarded. (Garhammer M. 2002) supposes that short period of time includes such types of activities, which have direct impact on energy restoration of Master's degree students. We can't completely share the opinion of Marquis and Huston (2009), who think that only event management and not time management is possible in life, and we consider that proper use of time resource causes formation of self-management culture (Kharadze N. Gulua E., 2016) Our article deals exactly with mentioned issues. Research was organized by Human Potential Management Laboratory (HPML) of TSU. Research was carried out in 5 leading universities of Georgia: Iv. Javakhishvili Tbilisi State University, Georgian Technical University, Gori State University, Telavi State University and Shota Rustaveli Batumi State University. Research was referred only to Master's degree students. Number of respondents amounted to 523. The questionnaire included 37 questions and 117 versions of answers. We laid an emphasis on that part of time budget, which doesn't represent the part of working time, in particular the time allotted for everyday rest, part of activities scheduled on Saturday and Sunday, time spent in social networks, personal hygiene, transportation, sport, physical activities, time devoted to sleep and nutrition. Research showed that in time budget of employed Master's degree students less attention is paid to free-time management that is the basis of increase of stress situations. Thus, conflict situation management among Master's degree students became the subject of consequent research of our laboratory. Except for employment or teaching activities, one has to devote certain time to personal life. Psychological or physical health predetermines better accomplishment of intended objectives. Proceeding from peculiarities of free-time management the recommendations were elaborated, which requires: development of self-management abilities, implementation of changes at organization level and amendments in the Law on Education System. In-depth study of time budget of Master's degree students is topical, since exactly these youngsters are potential labor resource of our country. Availability of healthy labor resources, in its turn, predetermines the potential of longterm development of organization and country as a whole.
\end{abstract}

Keywords: Time Management, Free-Time Management, Human Potential Management, self-management, stress Management

\section{Introduction}

Attitude to time management is becoming more actual in modern literature. (Orlikowsky \& Yates, 2002) The increase in the competition causes the need for effective use of time. The amount of free time is gradually decreased and its meaning is ignored in the employed graduates' time budget. Garhammer, M. considers that the activities that are directly affecting the recovery of the magistrates' energy are done in a short period of time. (Garhamer, 2002) The opinion that in our life it is 
possible to manage only events and not time (Marquis \& Huston, 2009), we do not fully share, and we believe that proper use of time resources causes a creation of self-management culture. (Kharadze, natalia; Gulua, Ekaterine, 2016) Our article is dealing with the above mentioned issues. The research was organized by Human Potential Management Laboratory. The survey was conducted at 5 leading universities in Georgia: Ivane Javakhishvili Tbilisi State University, Tbilisi Technical University, Gori State University, Telavi State University and Batumi Shota Rustaveli State University. The research was focused only on the MA students in Economics and Business Directions. The number of respondents was 523. The card included 37 questions and 117 options for answers. We focus on the part of the time budget that is not included in the amount of working time, namely the time allotted for daily rest, the share of events planned for the weekend, the time spent on social networking, personal hygiene, transportation, sport, physical activities, sleep and eating.

Besides performing work or learning activities, people must give some time to themselves and their personal lives. Psychological or physical health determines a better performance of the set goals.

"It is true that management is an essential part of governance, but leaders are not always effective leaders at this time. An effective leader is someone who can influence others in some ways or manners. A student who cannot manage himself/herself, which directly means not being able to manage time, will not be able to manage someone else. (Kharadze, Natalia; Amyoladze, Gocha, 2014)

Rational use of time is important for students because this is a stage for professional and moral formation, a period of establishment in the community (Kharadze, natalia; Gulua, Ekaterine, 2016) Time management is the one of main challenges of students, who have many ather challenges caused by system problems of higher education (Gulua, Ekaterine, 2017)

Due to this fact, an in-depth survey of the time spent on the MA students is very important, because they represent potential labor resources of the country. Healthy labor resources determine a long-term future development potential of the organization and the country. MA students' wish is to become leaders, The main phenomenon in the governance is a leader, who is active, emphatic, emotional, knowledgeable and educated, honest, and most importantly the existence of followers based on its main character activity, encouraging success and influencing them. However, by incorrect distribution of time, they may get sick and their goals remain unrealized. (Kharadze, Natalia; Amyoladze, Gocha, 2014) Georgian MA students have special opportunities in a tourism sector, because Georgia is annually becoming more and more appealing to foreigners. (Kharadze, Natalia; Korganashvili, Larisa, 2014) Future masters are allowed to work in foreign companies, the number of which is growing. In foreign companies it is necessary for them to adjust to a different rhythm of life which means effective time consumption.

While doing our research, we focused on 2 parts of time. One was directly related to the time spent on work since the majority of MA students are employed full-time and it also included the time to attend lecture-seminars and to study disciplines. The second part is free time in which we meant time for nutrition, sleep, sports activity, weekend rest.

We will pay attention to the analysis of the second part, because we think that in the age group of MAs it is important to use free time correctly to restore the energy spent by them. This will enable them to increase labor productivity with resource. Interestingly, the attitude MA students have towards the time management is also influenced by the cultural characteristics of the country and the region. Relationship to free time is different in different countries (Kharadze, Natalia; Chikhradze, Kakhaber, 2015) Special attention to free time management is even more interesting, since $85.5 \%$ of respondents indicate that they don't have enough time and only $14.5 \%$ are satisfied with their time. Let's assume that they are the students who are not employed or work part-time. See Table 1.

Table 1. Quality of satisfaction with the time resource of Mas

\begin{tabular}{|l|l|l|l|l|l|}
\hline \multicolumn{2}{|c|}{} & Frequency & Percent & Valid Percent & Cumulative Percent \\
\hline \multirow{4}{*}{ Valid } & Time is enough for me & 76 & 14.5 & 14.5 & 14.5 \\
\cline { 2 - 6 } & Is sometimes enough & 306 & 58.5 & 58.5 & 73.0 \\
\cline { 2 - 6 } & Is never enough & 141 & 27.0 & 27.0 & 100.0 \\
\hline
\end{tabular}




\begin{tabular}{|l|l|l|l|l|}
\hline & Total & 523 & 100.0 & 100.0 \\
\hline
\end{tabular}

Systemic time deficiency is a very strong stress that affects health: immune system is weakening, the risks of diabetes, ulcer, cardiovascular, tumor and other diseases are increasing. Managing yourself means that you can manage the special and normalized resource that is called time. Proper management of time means fulfilling your activities effectively and achieving the goal with less expenditure. From the well-known time management systems Franklin's pyramid, Covey's time management matrix and David Allen's Getting Things Done (GTD) I will focus on American Peter Drucker, who indicates in his book "The Effective Executive" that time management and management are closely linked to each other (Drucker, 1967). We will add on our side that self-management should also be considered in connection with them. If you cannot manage your own time, you cannot manage yourself and therefore cannot manage anything and anyone.

It is also interesting that the majority of the interviewed MA students are employed full-time (76\%) and accordingly are at work from 9 am to $6 \mathrm{pm}$. Approximately the number of unemployed graduates is equal to the amount of MA students content with their time. The employed students have to spend more time on transportation during the day, because they go to work first and then to university. Obviously, the transportation time could be considered as a sort of relax, but most of the respondents have to spend several hours to travel because they have to be in traffic jams after working hours. See Table 2.

\begin{tabular}{|l|l|l|l|l|l|}
\hline \multicolumn{2}{|l|}{ Table 2. Time spent on transportation } & Frequency & Percent & Valid Percent & Cumulative Percent \\
\hline \multirow{2}{*}{ Valid } & Up to one hour & 172 & 32.9 & 32.9 & 32.9 \\
\cline { 2 - 6 } & 1 -2hours & 271 & 51.8 & 51.8 & 84.7 \\
\cline { 2 - 6 } & 3 -4hours & 65 & 12.4 & 12.4 & 97.1 \\
\cline { 2 - 6 } & More than 4hours & 14 & 2.7 & 2.7 & 99.8 \\
\cline { 2 - 6 } & 5 hours & 1 & .2 & .2 & 100.0 \\
\cline { 2 - 6 } & Total & 523 & 100.0 & 100.0 & \\
\hline
\end{tabular}

As a result of the analysis, it was estimated that the average time spent by MA students on the transportation is 2 hours from their time budget. Only $0.2 \%$ of the respondents do not have to travel. These are the students who do not work and live in the university dormitory.

It is interesting how MA students understand the importance of free time and if they plan it. As it turned out while distributing the time resource the majority of the students do not plan free time. See Table 3. As a result of the survey, only 25.9 percent of respondents often plan how to spend free time and 71,1 percent sometimes or never plan it. This picture is also aggravated by the fact that a large number of respondents cannot find time to relax even on weekends. The use of free time and a healthy lifestyle are the factors that affect the development of healthy labor resources. Thus, in this regard, we have introduced a number of questions in the questionnaire which give us an idea about the attitude of the MA students towards a healthy lifestyle. The healthy lifestyle implies the behavior that positively affects the health of human beings, that means that the healthy lifestyle itself includes all the elements of behavior.

\begin{tabular}{|l|l|l|l|l|l|}
\hline \multicolumn{2}{|l|}{ Table 3. Frequency of Free Time Planning } & Frequency & Percent & Valid Percent & Cumulative Percent \\
\hline \multirow{2}{*}{ Valid } & Often & 135 & 25.8 & 25.9 & 25.9 \\
\cline { 2 - 6 } & Sometimes & 236 & 45.1 & 45.2 & 71.1 \\
\cline { 2 - 6 } & Hardly ever & 151 & 28.9 & 28.9 & 100.0 \\
\cline { 2 - 6 } & Total & 522 & 99.8 & 100.0 & \\
\hline Missing & System & 1 & .2 & & \\
\hline Total & & 523 & 100.0 & & \\
\hline
\end{tabular}


Despite the low level of free time planning, it is noteworthy that respondents manage to spend time in social networks. The social network has both positive and negative sides as well. Through this students can save time and connect with many people, get lots of information. Along with the positive sides it has its negative sides. Often there are occasions when social networks have a negative impact on the human psyche. Despite the lack of sufficient time resource, most of our respondents spend more time on social networking. In particular, only $40 \%$ spend one hour and the rest spend more than 2-3 hours. It is a subject of a separate research with what activities are they busy in social networks. Unfortunately, this question is not in our field of research. If we rely on the question in the questionnaire, from which we can find out that employed MA students are content with the materials provided by the lecturer and are less familiar with other materials, we can conclude that the majority of them don't use social networks for professional purposes.

Against the background of learning and employment, the overloaded day regime is a great risk to emerging stresses. In such circumstances it is not a social network but a physical activity which is a means of relaxation. This gives them the opportunity to restore energy and not switch from the natural condition of fatigue to the chronic conditions, since releasing chronic tension is not possible without a doctor's intervention.

What is the attitude towards sport? See Table 4 . Nearly $82 \%$ of respondents have never been engaged in sport activities and the level of daily physical activity is higher, in particular, only $8 \%$ do not do exercises at all.

Table 4. Sports activity Indicator

\begin{tabular}{|l|l|l|l|l|l|}
\hline \multicolumn{2}{|l|}{} & Frequency & Percent & Valid Percent & Cumulative Percent \\
\hline \multirow{2}{*}{ Valid } & Up to half an hour & 352 & 67.3 & 67.3 & 67.3 \\
\cline { 2 - 6 } & Up to 1 hour & 109 & 20.8 & 20.8 & 88.1 \\
\cline { 2 - 6 } & More than 1 hour & 43 & 8.2 & 8.2 & 96.4 \\
\cline { 2 - 6 } & More than 2 hours & 15 & 2.9 & 2.9 & 99.2 \\
\cline { 2 - 6 } & 5 hours & 4 & .8 & .8 & 100.0 \\
\cline { 2 - 6 } & Total & 523 & 100.0 & 100.0 & \\
\hline
\end{tabular}

With the enhanced loading background, students' sleep is important. Insufficient sleep reduces resistance to stress. It is known that $80 \%$ of stress causes the disease of cardiovascular, nervous, gastrointestinal and other organ systems. As a result of the overloaded schedule and addiction to social networking, young people's sleep regime is also violated. See Table 5. The study shows that only $29 \%$ sleep for $8-9$ hours, and about $75 \%$ sleep for $5-6$ hours. It is also alarming that only about $25 \%$ manage to sleep before 12 o'clock, especially when most of the students have to be at work at 9 o'clock the next day. The optimal period recommended for sleep is between $22-23 \mathrm{pm}$ and 6-7 am. The data are even getting worse because the full majority of respondents start working at 9-10am which means that either they do not arrive in time in working places or they are sleepy and without energy, accordingly their labor productivity in such a case obviously will be very low.

\begin{tabular}{|l|l|l|l|l|l|}
\hline \multicolumn{6}{|l|}{ Table 5. Sleep Duration in MA Students' Time Budget } \\
\hline \multicolumn{2}{|l|}{} & Frequency & Percent & Valid Percent & Cumulative Percent \\
\hline \multirow{3}{*}{ Valid } & Less than 5 hours & 43 & 8.2 & 8.2 & 8.2 \\
\cline { 2 - 7 } & $6-7$ hours & 350 & 66.9 & 66.9 & 75.1 \\
\cline { 2 - 7 } & $8-9$ hours & 123 & 23.5 & 23.5 & 98.7 \\
\cline { 2 - 6 } & More than 9 hours & 7 & 1.3 & 1.3 & 100.0 \\
\hline
\end{tabular}




\begin{tabular}{|l|l|l|l|l|}
\hline Total & 523 & 100.0 & 100.0 & \\
\hline
\end{tabular}

In our study, the MA students' eating frequency was also included. One of our criteria for proper nutrition is the frequency of receiving food, which is the basis of eating culture, which is a necessary condition for good health and subsequently for successful activities. The picture is alarming. See Table 6 . From the data it becomes clear that only $2.6 \%$ of respondents manage to eat 4 times a day, which is considered to be a norm, and it is a sad reality that $23 \%$ of the students eat only once a day. Only $48 \%$ manage to eat twice a day. It is a subject of a separate study whether they get the amount of calories that are needed for human and especially for adolescents' development and maintaining health. Unfortunately, our study did not cover the determination of the food ration.

\begin{tabular}{|l|l|l|l|l|l|}
\hline \multicolumn{5}{|l|}{ Table 6. MA Students' Eating Frequency } \\
\hline \multirow{2}{*}{ Valid } & Once & 118 & 22.6 & 23.5 & Cumulative Percent \\
\cline { 2 - 6 } & Twice & 242 & 46.3 & 48.1 & 23.5 \\
\cline { 2 - 6 } & 3 times & 130 & 24.9 & 25.8 & 71.6 \\
\cline { 2 - 6 } & 4 times & 13 & 2.5 & 2.6 & 97.4 \\
\cline { 2 - 6 } & Total & 503 & 96.2 & 100.0 & 100.0 \\
\hline Missing & System & 20 & 3.8 & & \\
\hline Total & & 523 & 100.0 & & \\
\hline
\end{tabular}

We have formulated the following hypotheses:

H1: Gender, working in private or public sector, working with profession and working time in social networks have a significant impact on variables:

Q10 - How many hours do you attend lectures per day?

Q11 - How many lectures do you attend weekly and

Q8 - What time do you need to prepare lectures and seminars during a day?

H2: Gender affects variables: Q10 - For how many hours are you at the lecture per day?

Q11 - How many lectures do you attend weekly and Q8 - During the day how many hours do you need to prepare lectures - seminars.

H3: H3: Working in private or public sector affects variables: Q10 - For how many hours are you at the lecture per day?

Q11 - How many lectures do you attend weekly and Q8 - During the day how many hours do you need to prepare lectures - seminars.

H4: Working with a profession affects variables: Q10 - For how many hours are you at the lecture per day?

Q11 - How many lectures do you attend weekly and Q8 - During the day how many hours do you need to prepare lectures - seminars?

H5: Time for working on social networks affects variables: Q10 - For how many hours are you at the lecture per day?

Q11 - How many lectures do you attend weekly and Q8 - During the day how many hours do you need to prepare lectures - seminars?

It was interesting for us to evaluate the effect of social networking on the Q10, Q11 and Q8 variables during the day. 
As is shown in Table 7, working on social networks during the day affects the Q11 variable (about how many lectures/hours do you attend per week) with a statistically significant link on 0,05 level, $P=0,033, P<0,05$ )

\begin{tabular}{|l|l|l|l|l|l|l|l|}
\hline \multicolumn{2}{|l|}{ Table 7 Influence of social networking with attendance at the lecture: } \\
\hline \multirow{2}{*}{ Dependent Variable } & $\begin{array}{l}\text { Sum of } \\
\text { Squares }\end{array}$ & df & $\begin{array}{l}\text { Mean } \\
\text { Square }\end{array}$ & F & Sig. & $\begin{array}{l}\text { Partial Eta } \\
\text { Squared }\end{array}$ \\
\hline $\begin{array}{l}\text { Q10 How many } \\
\text { hours are you at } \\
\text { the lecture per } \\
\text { day? }\end{array}$ & $\begin{array}{l}\text { How many hours do you spend } \\
\text { on social networking per day? }\end{array}$ & 1,334 & 3 & 0,445 & 0,921 & 0,430 & 0,006 \\
\hline & Error & 228,753 & 474 & 0,483 & & & \\
\hline $\begin{array}{l}\text { Q11. How many } \\
\text { lectures/hours do } \\
\text { you attend weekly? }\end{array}$ & $\begin{array}{l}\text { How many hours do you spend } \\
\text { on social networking per day? }\end{array}$ & 25,559 & 3 & 8,520 & 2,939 & 0,033 & 0,018 \\
\hline & Error & 1373,825 & 474 & 2,898 & & & \\
\hline $\begin{array}{l}\text { Q8 During the day } \\
\text { how many hours } \\
\text { do you need to } \\
\text { prepare lectures - } \\
\text { seminars? }\end{array}$ & $\begin{array}{l}\text { How many hours do you spend } \\
\text { on social networking per day? }\end{array}$ & 1,842 & 3 & 0,614 & 1,514 & 0,210 & 0,009 \\
\cline { 2 - 12 } & Error & 192,253 & 474 & 0,406 & & & \\
\hline
\end{tabular}

A weak positive attitude ( $r=0.137$, table 8 ). So the fifth hypothesis was fulfilled partly to the Q11 variable.

\begin{tabular}{|c|c|c|c|c|c|}
\hline \multicolumn{6}{|c|}{ Table 8 Correlations } \\
\hline & & $\begin{array}{l}\text { Q1 } \\
\text { Gender }\end{array}$ & $\begin{array}{l}\text { Q4 Besides studying do } \\
\text { you work in private or } \\
\text { public sector? }\end{array}$ & $\begin{array}{l}\text { Q19 How many hours do } \\
\text { you spend on social } \\
\text { networking per day? }\end{array}$ & $\begin{array}{l}\text { Q21 Do you work } \\
\text { with your } \\
\text { profession? }\end{array}$ \\
\hline \multirow{3}{*}{$\begin{array}{l}\text { Q8 During the day } \\
\text { how many hours do } \\
\text { you need to prepare } \\
\text { lectures - seminars? }\end{array}$} & $\begin{array}{l}\text { Pearson } \\
\text { Correlation }\end{array}$ & $-0.116^{* *}$ & $0.208^{* *}$ & 0.050 & $0.285^{* *}$ \\
\hline & $\begin{array}{l}\text { Sig.(2- } \\
\text { tailed) }\end{array}$ & 0.008 & 0.000 & 0.258 & 0.000 \\
\hline & $\mathrm{N}$ & 518 & 518 & 512 & 517 \\
\hline \multirow{3}{*}{$\begin{array}{l}\text { Q10 How many } \\
\text { hours are you at the } \\
\text { lecture per day? }\end{array}$} & $\begin{array}{l}\text { Pearson } \\
\text { Correlation }\end{array}$ & $-0.172^{* *}$ & $0.355^{* *}$ & $0.115^{* *}$ & $0.175^{* *}$ \\
\hline & $\begin{array}{l}\text { Sig.(2- } \\
\text { tailed) }\end{array}$ & 0.000 & 0.000 & 0.010 & 0.000 \\
\hline & $\mathrm{N}$ & 509 & 509 & 507 & 508 \\
\hline \multirow{3}{*}{$\begin{array}{l}\text { Q11 How many } \\
\text { lectures/hours do you } \\
\text { attend weekly? }\end{array}$} & $\begin{array}{l}\text { Pearson } \\
\text { Correlation }\end{array}$ & -0.040 & $0.355^{* *}$ & $0.137^{* *}$ & $0.139^{* *}$ \\
\hline & $\begin{array}{l}\text { Sig.(2- } \\
\text { tailed) }\end{array}$ & 0.366 & 0.000 & .002 & 0.002 \\
\hline & $\mathrm{N}$ & 513 & 513 & 509 & 512 \\
\hline
\end{tabular}

By means of filtration we have only selected the students who work in private or public service and analyzed the social condition of employed students. In particular, the following types of data are available for married and single students through the consumer table: salary, duration of sleep, whether they have the time allotted for rest, how many times they eat a day properly. We got the following picture (Table 9).

According to the 9th table, the number of employed students is $427 ; 72$ are single and 450 are married, most students 212 single students and 40 married students have more than $500 \mathrm{GEL}$. 


\begin{tabular}{|c|c|c|c|c|}
\hline & & \multicolumn{2}{|c|}{ Q18 Marital Status } & \multirow{3}{*}{ Total } \\
\hline & & Married & Single & \\
\hline & & Frequency & Frequency & \\
\hline \multirow[t]{6}{*}{ Q28 What is your salary? } & Up to $100 \mathrm{Gel}$ & 1 & 11 & 12 \\
\hline & From 100GEL - to $200 \mathrm{GEL}$ & 1 & 8 & 9 \\
\hline & From $200 \mathrm{GEL}$ - to $300 \mathrm{GEL}$ & 2 & 25 & 27 \\
\hline & From 300 GEL - to 400 GEL & 4 & 41 & 45 \\
\hline & From $400 \mathrm{GEL}$ - to $500 \mathrm{GEL}$ & 10 & 60 & 70 \\
\hline & More than $500 \mathrm{GEL}$ & 40 & 212 & 252 \\
\hline \multicolumn{2}{|l|}{ Total } & 58 & 357 & 415 \\
\hline \multirow{4}{*}{$\begin{array}{l}\text { Q29 How many hours do you } \\
\text { sleep? }\end{array}$} & Less than 5 hours & 6 & 35 & 41 \\
\hline & 6-7 hours & 43 & 261 & 304 \\
\hline & 8-9 hours & 10 & 71 & 81 \\
\hline & More than 9 hours & 0 & 1 & 1 \\
\hline \multirow[t]{3}{*}{$\begin{array}{l}\text { Q16 Do you have time } \\
\text { allotted for a rest per day? }\end{array}$} & Often & 8 & 93 & 101 \\
\hline & Sometimes & ,24 & 174 & 198 \\
\hline & Almost Never & 27 & 101 & 128 \\
\hline \multirow{4}{*}{$\begin{array}{l}\text { Q33 How many times do you } \\
\text { eat properly per day? }\end{array}$} & Once & 14 & 93 & 107 \\
\hline & Twice & 26 & 177 & 203 \\
\hline & 3 times & 14 & 77 & 91 \\
\hline & 4 times & 0 & 10 & 10 \\
\hline
\end{tabular}

When asked about sleeping duration most employed students from both categories (married and single) answered the question about sleeping duration and indicate that they sleep for about 6-7 hours.

When asked whether they have the time allotted for a rest per day, most of the single students (174 students) indicate that they sometimes have time for a rest during the day and most of the married students unfortunately have almost no time to relax. A large number of single students (101 students) also report the same.

And they were asked the last question - how many times they eat properly per day, most of both married and single employed students responded that they eat twice. No one from the married students has given a positive answer to the category- 4 times.

While building a consumer table by means of statistics we had an opportunity to define a connection of marital status of students with the following variables: Q28 What is your salary? Q29 How many hours do you sleep? Q16 Do you have time allotted for a rest during the day? And Q33 How many times do you eat properly per day?

From the statistical table 10 we find that the marital status variable has a close statistical connection on 0.01 level $(P=$ 0.010), with the leisure time variable.

Table 11 shows a correlation between Q18 (marital status) and Q16 (Do you have the time for a rest during the day?) Variable. As is shown in the table, there is a weak negative correlation between these variables. 


\begin{tabular}{|l|l|l|}
\hline \multicolumn{2}{|l|}{ Table 10 Pearson Chi-Square Tests } & Q18 Marital Status \\
\hline \multirow{4}{*}{ Q28 How much is your salary? } & Chi-square & 3.077 \\
\hline & Df & 5 \\
\cline { 2 - 3 } & Sig. & $0.688^{\mathrm{a}}$ \\
\hline \multirow{3}{*}{ Q29 How many hours do you sleep during the day? } & Chi-square & 0.358 \\
\hline \multirow{2}{*}{ Q16 Do you have the time allotted for a rest during the day? } & Df & 3 \\
\hline & Sig. & $0.949^{\mathrm{a}, \mathrm{b}}$ \\
\hline \multirow{3}{*}{ Q33 How many times do you eat properly per day? } & Chi-square & 9.118 \\
\hline & Df & 2 \\
\hline & Sig. & $0.010^{*}$ \\
\hline & Chi-square & 1.935 \\
\hline & Df & 3 \\
\hline Sig. & 0.586 \\
\hline
\end{tabular}

\begin{tabular}{|c|c|c|c|}
\hline \multicolumn{4}{|l|}{ Correlations } \\
\hline & & $\begin{array}{l}\text { Do you have the time allotted for } \\
\text { a rest during the day? }\end{array}$ & Marital Status \\
\hline \multirow{3}{*}{$\begin{array}{l}\text { Do you have the time allotted for a } \\
\text { rest during the day? }\end{array}$} & Pearson Correlation & 1 & $-0.156^{* *}$ \\
\hline & Sig. (2-tailed) & & 0.000 \\
\hline & $\bar{N}$ & 522 & 522 \\
\hline \multirow{3}{*}{ Marital Status } & Pearson Correlation & $-0.156^{* *}$ & 1 \\
\hline & Sig. (2-tailed) & 0.000 & \\
\hline & $\mathrm{N}$ & 522 & 523 \\
\hline
\end{tabular}

This research provides a general picture about the time budget of the employed MA students in Georgia and offers general trends about time management. Since the results of the research are mainly given in the data of descriptive statistics, we present general recommendations that should be taken into consideration by an employed (MA) student to effectively organize the time. Part of these recommendations were formulated by Iv. Javakhishvili TSU Department of Psychology.

Objectives and prioritization. In addition to learning and career goals, personal goals, including: understanding social, emotional or financial goals, realizing their significance will also help the person to better prioritize its goals. Consequently, time planning more reasonably should be taken into account in order to achieve a certain goal.

It is important for people to remember keeping a balance between different goals. In addition to learning and working, it is necessary to have time for relaxing and daily household activities.

Planning of the activities and writing the list. It is Recommended to have a book/notebook with a calendar, where all the important events: the date of exams, the timing of submitting reports at work, short term goals and other events will be written down.

Making a schedule of activities is desirable for the effective management of a limited amount of time. Every evening it is possible to find 10 minutes to write a list of activities for the next day, what you need to do and how much time you actually have: to find the literature for an abstract or choose a birthday gift for a friend.

It is important to order a list of activities according to priorities. You can specify the time duration or the specific day section for each activity.

However, it is important to have flexibility, make some corrections in the list, remove or add some activities.

Avoiding postponing of doing things $\sim$ It is not recommended to postpone the various difficult or boring tasks. Often instead of starting a whole project, we procrastinate and do nothing. As a result, a person may have qualms of conscience and anxiety. 
To avoid this habit, it is desirable to think about the negative aspect of putting off something before the last minute. If it is not possible to finish the entire project at once, it is better to divide it into smaller parts and perform separately.

Concentrating on the learning process - It is recommended to relax for a short time before starting to learn. It is necessary to allocate specific time for studying and it is desirable this period to be the same every day. It is better to choose a quiet and comfortable place for studying. It is desirable to turn off the phone, TV and other devices, as well as switch off the various social networks so that people can be fully focused on the studying. Since it's easy to lose attention, that's why it is important for people to think only about the study material and not about job related things.

Allocating time for yourselves. In addition to performing work or learning activities, people must give some time to themselves and their personal lives. Being psychologically or physically well ensures better fulfillment of the set goals.

Eating: It is necessary to eat properly. Some food and substance increases stress and anxiety, while others reduce them. It is recommended to reduce caffeine, nicotine, animal fat; to get a lot of water, vegetables, cereals. It is necessary to get food at least twice a day and the last meal should not be later than $8 \mathrm{pm}$.

Exercise: Physical activity improves blood circulation, focus concentration, sleep and generally - health; it reduces stress, encourages releasing endorphins, which leads to feeling of being well.

Sleep: It is better to sleep and wake up at the same time. Sleep duration is recommended from 7 to 9 hours. If you do not sleep enough regularly, the concentration capability, the efficiency of memory, general cognitive functions and the energy level decrease, the stress increases.

Relationships: Despite the busy schedule, social relationships should not be stopped. If the schedule allows you, find some time every week to meet your friends or enjoy with your family.

\section{References:}

It is important for people to realize that it is impossible to satisfy and fulfill all the wishes and goals at once. Developing time management skills is not easy, it takes time. Sometimes people are not able to keep balance. In this situation it is desirable to understand the positive and negative sides of the situation, evaluate the results and review possible alternatives. Sometimes people should forgive themselves if they could not do something in such a way as they meant to do, they will bring the goals to the end as soon as it is possible.

- After completing any item in the list of planned activities, it is desirable to reward yourself, even with a little bit. For example, if you finish an important task at work, you can reward yourself with visiting friends.

- Considering the interests of the MA students who are employed by the organizations will have the sense of belonging to the organization and the use of their own potential in favor of the organization. (Gulua, Ekaterine; Kharadze, Natalia, 2014)

- At the legislative level it is important for employed MA students to be allowed to work part time.

- The study has shown that the employed MA students' time budget is less focused on managing free time, which is the basis for increasing stressful situations. Thus, conflict situations became the subject of further study in our laboratory.

\section{Bibliography}

[1] Drucker, P. F. (1967). The Effective Executive. New York: Harper \& Row.

[2] Garhamer, M. (2002). "Pace of life and enjoyment of life". Happiness Studies, 56.

[3] Gulua, Ekaterine. (2017). Modern Challenges of Higher Education. Economics and Business - Refereed and Reviewed International Scientific and Practical Journal, pp. 112-132.

[4] Gulua, Ekaterine; Kharadze, Natalia. (2014). Knowledge-Based Organizational Culture Development Challenges in Small and Medium Sized Enterprises of Post-Soviet Georgia. ADVANCES IN BUSINESS MANAGEMENT Towards Systemic Approach (pp. 90-94). PERUGIA: Business Systems Laboratory - All Right Reserved.

[5] Kharadze, N., \& Amyoladze, G. (2014). Globalization of research of factors of success of Georgian business leaders. Modern Issues of Medicine and Management (pp. 146-151). Tbilisi: GEOMEDI. 
[6] Kharadze, Natalia; Amyoladze, Gocha;. (2014). Leadership development features in conditions. Modern Issues of Medicine and Management (pp. 141-145). TBILISI: GEOMEDI.

[7] Kharadze, Natalia; Chikhradze, Kakhaber. (2015). Cultural Parallels Between Russia and Georgia and Their Effect on Women Employment. Culoture and Rassian Society. Helsinki: University OF Helsinki.

[8] Kharadze, Natalia; Gulua , Ekaterine;. (2016). Self-Management Peculiarities of Master's Students in Georgia. CHELLENGES OF GLOBALIZATION IN ECONOMICS AND BUSINESS (pp. 613-617). Tbilisi: UNIVERSAL.

[9] Kharadze, natalia; Gulua, Ekaterine. (2016). Self-Management Peculiarities of Masters' Students in Georgia. CHALLENGES OF GLOBALIZATION IN ECONOMICS AND BUSINESS (pp. 613-617). Tbilisi: UNIVERSAL.

[10] Kharadze, Natalia; Korganashvili, Larisa. (2014). Regional Project Management of Tourism Development in Georgia. Project Management Development - Practice and Perspectives (pp. 109-116). Riga: Riga,University of latvia.

[11] Marquis, B. L., \& Huston, C. J. (2009). "Leadership roles and management functions in nursing: theory and application". Wolters Kluwer Health.

[12] Orlikowsky, W. J., \& Yates, J. (2002). "Its about time: temporal structuring in organizations". Organization Science, 684-700. 